\title{
A Study on the Qualitative Simulation of Consumer Behavior under the Environment of Electronic Commerce
}

\author{
Meilian Liu \\ Management College, Guilin University of Electronics and Technology, Guilin 541004, P.R. China
}

\begin{abstract}
The paper focuses on the qualitative simulation of consumer behavior under the environment of electronic commerce. The foundation of the qualitative simulation system is consumer attitude theory, consumer psychology, sociology and economics, and the system is oriented to how consumer behavioral intention has been formed. According to consumer behavior characteristics, the qualitative simulation system has been designed based on qualitative simulation and qualitative process theory. The system mainly consists of three modules: consumer perceived utility, consumer attitude and consumer intention module. By Visual Basic, the system function of qualitative simulation in the competitive markets has been fulfilled in the paper.
\end{abstract}

Keywords: Electronic commerce, Qualitative simulation, Consumer behavior, Expert knowledge base

\section{Introduction}

E-commerce is a type of electronic trade based on advanced computer network technology and communication technology platform, which brings a dramatic change of the concept of traditional market in its qualitative area for both the time scale and spatial dimension. E-commerce makes the market boundaries dimmer owing to the difference among the traditional geography, political opinion, and ideology. The rapid development of E-commerce has drawn a vast attention from government, enterprises and academic scholars, and the researches focus on two aspects: electronic commerce technology and marketing management under the environment of e-commerce. For marketing management, the key research point lies in the modeling of consumer behavior. However, the consumer demand and behavior are so complicated that it is almost impossible to establish completely quantitative model because we can hardly collect all the precise data on product sales revenue, related marketing activities and large quantity of customer information, we can only do quantitative analysis to make all the possible predictions of consumer behaviors based on many suppositions. Taken the innovation diffusion model for an example, it is generally accepted that advertisement media is relative to the consumer innovation diffusion process, but there are disagreements on how advertisements have effect on the adaptors, it is not certain whether the advertisements make the external environment change so dramatically that the consumers adopt the innovation or the advertisements make the communication among the consumers so smooth that the adoption activities take place. However, no matter what kind of advertisement diffusion mode, it is no doubt that the innovation diffusion is related to the advertisement. For qualitative simulation, only to make such simple supposition that the innovation diffusion is related to advertisements is enough not to define the precise mathematical function.

Different from previous studies which focus on the consumer decision process, we have explored a new method of integration consumer attitude, sociology with economics together, which is to treat the consumer decision process as the process of how the consumer intention has been formed. So to combine qualitative simulation theory with qualitative process theory, qualitative simulation has been done based on the efforts of consumer behavior, social, economics and psychology according to the characteristics of consumer behavior in this paper.

The paper structure is arranged as follows: the first is the related work review; the second is the theories related to the qualitative simulation of consumer behavior; the third is the modeling and implementation of qualitative simulation system of consumer behavior; finally is conclusion and remarks.

\section{Related work review}


Simulation is a young and developing fast field in social science. With the advent of program language, some social scientists became eager to understand the behavior process by computer models. Newell, Shaw and Simon put forward a human problem solution theory which resembled computer program. This theory consists of three parts: a control system which is made up of mass memory; initialization process stored in memorizer and perfect rule definition. Horland found that the way of human being solving problem resembles the way of the computer by comparison the way of Euclidean algebra solution in 1960. Colby and Watt developed a neuropath simulation information system, in which doctors and patients can talk to each other in 1966 [1].

Although people placed quite high expectation on computer simulation in the 1960s, computer simulation did not flourish in social and behavioral science field. Until the 1990s, with the increase of computer procession speed, lots of scholars picked up simulation as a tool to study different social process again. Owing to the broad field in social science, a lot of simulation models swell up recently from pure game theory simulation to the micro world simulation in social science. However, no clear social scientists group in computer simulation has come into being. Axelord thought that it was due to the fact that simulation efforts scattered in other magazines besides social magazines, and simulation purpose focuses on three points: process forecast, principle test and result discovery [2]. Simulation in social science is often divided into four types. The first aims to describe a definite real world system. Generally such simulation is used to study the interaction between human being and simulation system, in which complex resources are also faced with the dilemma of decision-making like human beings. The second pays attention to decision rules by agent. The third is about the interaction between agents and environment. The forth is the qualitative simulation which is a new method when social scientists have difficulty in setting up completely quantitative models.

Qualitative simulation has been broadly used in qualitative physics and ecosystem, for example, Daniel Berleant discussed the application of qualitative simulation by introducing a case of tub and spring[3] , and Cuerrin took a salmon example to demonstrate the specific use of it[4]-[5].

Since QSim is comparatively weak in forecast capability, some scholars have extended QSim to $\mathrm{Q}_{2}$ and Q3 by providing proper quantitative information or integrating it with other quantitative methods so as to improve its simulation capability. These methods used frequently are probability, interval analysis, discrete time simulation, fuzzy mathematics method and so on, which could reduce the number of solutions to the problem caused by abstract information due to pure qualitative analysis. The combination of qualitative and quantitative methods opened a new field for qualitative reasoning research work [6]-[7]. De Kleer pointed out that it is a trend to integrate qualitative reasoning with traditional algebra, interval algebra, numerical simulation and system dynamics [8]. At the beginning of qualitative reasoning, Forbus thought that it would have great potential for qualitative reasoning in the economics [9]. And now, it has played an important role in the economics and decision-making. Kiang and other researchers carried out a qualitative simulation of economic system by integrating qualitative reason with economic model [10]. Wolfgang Balzer designed an arithmetic based on the qualitative model of planed international crisis so as to forecast whether a given state was the root of an international crisis or not [11].

To consider probability in forecasting subsequence condition, Chinese scholar Bai Fangzhou set forward BFQS fuzzy simulation method which improved the reliability and greatly reduced the problem of different meanings of qualitative simulation [12]. Liang Changyong improved the arithmetic of QSIM to put forward the restrictions and target search strategy, and simulated Keynesian dynamic economic model by modified QSIM arithmetic [13]. Wang Dongfeng used object-oriented method and fuzzy simulation techniques to improve the efficiency of traditional qualitative simulation [14]. $\mathrm{Hu}$ Bin analyzed marketing decision-making based on qualitative relationship [15], but did not refer to consumer behavior simulation in e-commerce environment.

In economic behavior research, we can not always get precise quantitative information, which makes it proper even necessary to adopt qualitative techniques. Of course, quantitative simulation is still a proper and effective reason method if precise mathematical information could be obtained. Since it is very difficult to analyze the complex factors related to consumer behavior by establishing completely quantitative model, qualitative simulation modeling for consumer behavior is justified.

\section{Theory Related to Consumer Behavior Qualitative Simulation}

Consumer behavior is related to various fields such as marketing, psychology, sociology and economics. This paper integrates efforts in different fields together 
to construct a qualitative simulation system in the ecommerce competition.

In view of attitude and behavior theory, consumer behavior is the result from their attitude, the most famous one of all attitude and behavior theories is the theory of reasoned action (TRA) put forward by Fishbein and Ajzen which is mainly used to predict and understand individual consumer behavior supposing that an individual has capability of controlling himself completely. Theory of planned behavior (TPB) extended this theory to take people's incapability of self-control into consideration. In this theory, behavior is the function of intention and perceived behavior control and intention is based on behavior attitude, subjective standard and perceived behavioral control.

From perspective of psychology, consumer decision is caused by information procession and brand comparison. In marketing research, it is often to put emphasis on the consumer decision process to describe and predict the consumer behavior especially in consumer loyalty and advertisement effect according to learning theory and reward theory.

In view of sociology, consumer behavior is a kind of activity related to social relationship in which different groups are reciprocal. Consumer decision is influenced by the group whom the consumer belongs to greatly and less influenced by the other groups. The groups influence their members in three aspects: information, social standard and value.

In view of traditional economics, consumer behavior is a process based on the rational choice by evaluation of price and information search cost. A rational consumer is always trying to maximize his utility. However, he can only obtain satisfied utility instead of maximization utility due to the reality restrictions.

From perspectives of behavioral economics, consumer decision is a bounded rationality. Consumer choice is related to the cause mechanism which will result in the consumer decision. Consumer choice is the probability of a specified behavior based on the competitive environment, so consumer choice is not the result of a single event but a probability distribution in a period. How to choose is often from promotions or punishments in the surroundings instead of detailed consideration.

\section{Construction of Consumer Behavior Qualitative Simulation System}

\subsection{Several Suppositions in Qualitative Simulation System}

The characteristics of consumer behavior have varied dramatically under the environment of e-commerce. According to related theoretical research on consumer behavior, this paper makes some basic suppositions as follows in view of market environment and consumer behavior influencing factors.

\subsubsection{Bounded rationality supposition}

Consumer belongs to bounded rationality human beings, who try to maximize their utility in the restricted resources and conditions. Because of large quantities of information in Internet, it is impossible and unnecessary for consumers to search all the information related to products or service and to compare those information so as to maximize their utility, which means that they could only obtain proper utility to some extent.

\subsubsection{Competitive marketing environment supposition}

Consumers are always in a competitive marketing environment. Restricted by some specific social moral and regulations, consumers could freely choose products and service that they need.

\subsubsection{Product market supposition}

The market economy has developed mature, where the products supplied are abundant enough to satisfy their needs without any risk of product inadequacy.

\subsubsection{Consumer behavior characteristics supposition}

Different purchase mode is driven by different consumer attitude, which means that even in the same background, consumer decision shows difference when their attitude characteristics is not the same. Consumers can be divided into three types: innovators, imitators and laggards. Innovators are those who hold a positive attitude toward e-commerce in early times, and imitators are stimulated by innovators and become gradually positive towards e-commerce, and laggards are the last to adopt e-commerce

\subsection{Qualitative Simulation System of Consumer Behavior}

According to the characteristics of consumer demand behavior and consumer behavior attitude model under the environment of electronic commerce, a consumer behavior qualitative simulation model which focuses on how consumer intention has been formed has been set forward by integration research efforts of consumer 
behavior in various fields such as psychology, classical economics, behavior economics and sociology together, which is not completely from the previous consumer behavior research model which is oriented to the consumer decision process. The consumer decision-making models often tend to treat consumer's choice as a very complex decision process, which comprises of five stages: problem recognition, information search, evaluation and comparison, purchase and post-purchase evaluation. However, this kind of research is not easily operative. The qualitative simulation system is shown in Fig.1.

From Fig.1, we can see that consumer behavior qualitative simulation system is mainly made up of three modules: (1) perceived utility module by web consumer. (2) How consumer attitude has been formed (3) the consumer intention process. This paper takes perceived utility to be main source of consumer attitude, and consumer intention shows significant correlation with consumer attitude, while decisionmaking only comes into being after consumer behavior intention has been created, and consumer demand has been intensified.

In the environment of e-commerce, consumers pursue their individualized needs for varied products and service. Only when consumer attitude reaches a specific threshold, behavioral intention will come into being and decision will be made by the promotion of need. The after-purchase evaluation of products and service which the consumer has purchased will be related to repeated purchase. In the same time, the consumer purchase decision has effect on the enterprises' products share and net enterprises' brand images.

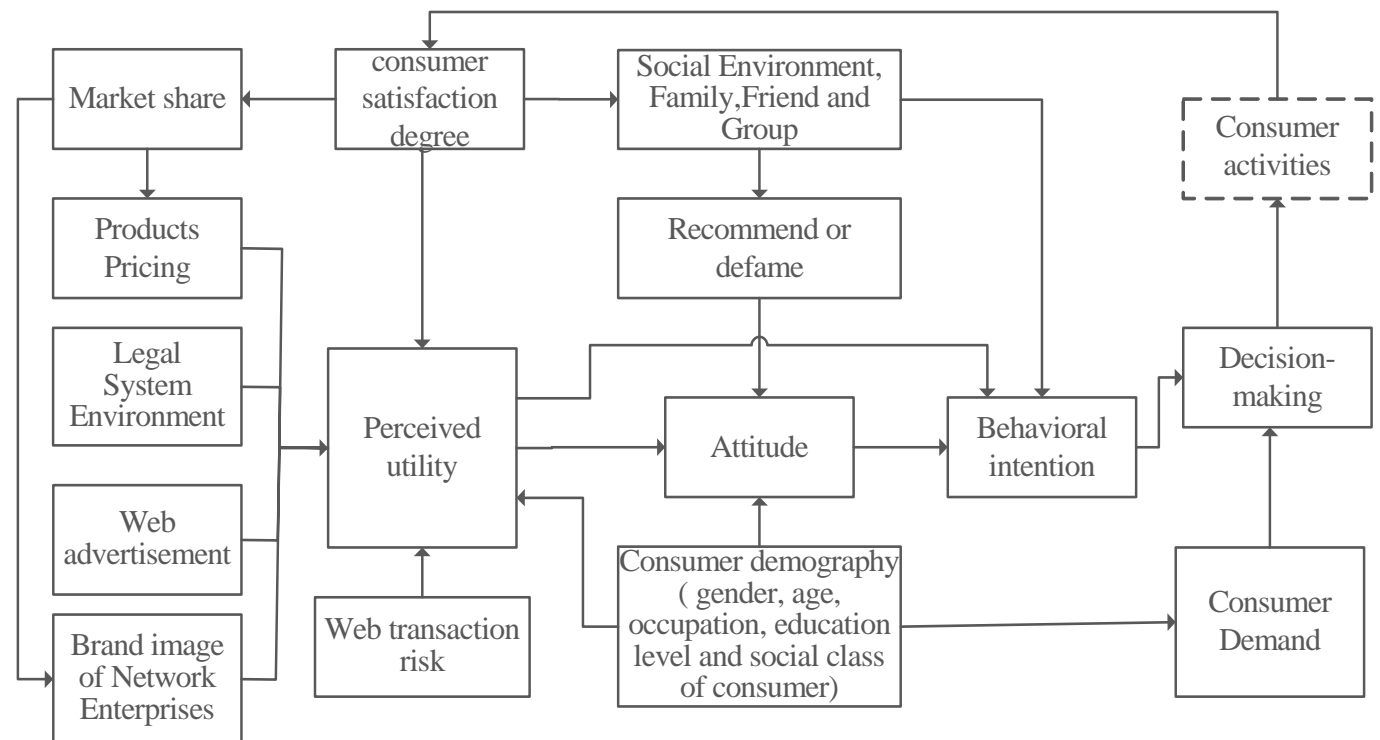

Fig. 1: The qualitative simulation system.

\subsection{Development of the prototype system in the consumer behavior qualitative simulation}

\subsubsection{The causal reason in the qualitative simulation of consumer behavior}

According to qualitative process theory, the causal relation among variables could be expressed in two ways, one is positive direction and the other is negative, for example, $v \succ^{+} w$ means $\mathrm{v}$ has positive direction effect on $\mathrm{w} ; v \succ^{-} w$ means $\mathrm{v}$ has negative direction effect on w. If a few processes have effect on one variable, the whole effects could be calculated by operator $\oplus$.

In the qualitative simulation system, we put emphasis on perceived utility (PU), consumer attitude (AT) and consumer's behavior intention (INT). Now, supposing that the state space for the variables PU, AT and INT is $\{2+, 1+, 0,1-, 2-\}$, other factors state space is $\{+, 0,-\}$. In the state space for PU, " $2+$ ” stand for rising up fast, “+” means rising slowly, “0”means invariability, “_”means falling down, “2-”means falling down fast, and so do other variables state space. We only focus on how consumer attitude characteristic caused by varied product and service price, web advertisement and human relations in the competitive market, while the legal system environment and 
demography characteristics of consumers in the simulation time could be considered invariable.

In the qualitative simulation system, we should also consider variable magnitude, and qualitative state is expressed as QS (V, T(i), $<\mathrm{L}, \mathrm{D}>$ ), of which $\mathrm{V}$ stands for variable name. In dynamic system, the new stage value of variable $\mathrm{L}$ is determined by former stage and increments in a new stage, In this research, qualitative value of every direction could be divided into three levels, big, medium and small, various levels are divided into three sub-levels, the total state of variables is 9, which amounts to HH0, MM3, MM2, MM1, MM0, ML3, ML2, LL0.

If consumer attitude state in $\mathrm{T}$ (i) is known, then the $\mathrm{D}$ values of attitude in $\mathrm{T}(\mathrm{i}+1)$ could be calculated according to qualitative algorithms. Consumer perceived utility PU and consumer's attitude D value could be calculated as follows:

$$
\begin{aligned}
& Q S(P U, t(i+1), D)=Q S(A D, t(i+1), D) \\
& \oplus Q S(\mathrm{~L} a w, t(i+1), D) \oplus Q S(P, t(i+1), D) \\
& \oplus Q S(C S, t(i), D) \oplus Q S(B R, t(i+1), D) \\
& \mathrm{QS}(A T, t(i+1), D)=Q S(P U, t(i+1), D) \\
& \oplus Q S(S S, t(i+1), D) \oplus Q S(C D, t(i+1), D)
\end{aligned}
$$
see table1.

For the definition of qualitative operator $\oplus$, please

\begin{tabular}{|c|c|c|c|}
\hline$\oplus$ & + & - & 0 \\
\hline+ & + & $\{+, 0,-\}$ & + \\
\hline- & $\{+, 0,-\}$ & - & - \\
\hline 0 & + & - & 0 \\
\hline
\end{tabular}

Table.1: Qualitative operation table.

When the qualitative calculation result appears as $\{+, 0,-\}$, it means there may be three results, to rise up, to fall down or to remain unchanged. In order to obtain a certain result, we define $\operatorname{STRD}(V)$ to be the intensity of $\mathrm{D}$. If $\operatorname{STR}(D(V)) \approx S T R(D(W))$, when $D(V)=-$ and $D(W)=+, D(V) \oplus D(W)$ could be neglected.

\subsubsection{Process knowledge base design for the consumer behavior qualitative simulation}

Based on the consumer behavior qualitative simulation shown in the fig. 1 , the process knowledge base of the consumer behavior qualitative simulation has been designed according to the methods mentioned above, which is shown in table 2 .

Process $P$ (1) stands for how perceived utility has been formed. Estimation of perceived utility depends on the consumer satisfaction degree in the former stage, web advertisement, product price, web enterprise image and perceived online trade risk in this stage. For varied attitude types of consumers, the changes of web advertisement and price have varied effect on perceived utility. For innovators, they are less sensitive to the price change, but more sensitive to web advertisements than imitators and laggards. Now, we suppose that the qualitative strength of web advertisement on innovators' perceived utility is 2; while the qualitative strength of price is 0 . However, qualitative strength of web advertisement on laggards' perceived utility is 0 ; while the qualitative strength of price is 2. The qualitative strength of web advertisement and price on imitators' perceived utility is both 1 . In order to reduce branches caused by simulation results, supposing that for all consumers, any changes in consumer satisfaction and online trade risk have the same impact on consumer's perceived utility. Part of expert knowledge base of estimated perceived utility of innovators is shown in table 3 .

Process P (2) shows how consumer attitude has been formed. Consumer attitude depends on the estimation of consumer perceived utility and social environment in current stage. Therefore, $Q S\left(A T, T_{(\mathrm{i})}, D\right)$ $=Q S\left(P U, T_{(\mathrm{i})}, D\right) \oplus Q S\left(S S, T_{(\mathrm{i}-1)}, D\right)$. In order to reduce branches caused by simulation results, we assume qualitative strength of consumer perceived utility is bigger than that of social environment. On condition that consumer's demographic characteristics do not change, the part of expert knowledge base of consumer's attitude originated from consumer's perceived utility and social environment is shown in table 4.

Process P (3) shows the process of how consumer behavioral intention has been created. Consumer behavioral intention relies on consumer behavior attitude and social environment, so QS(INT,T(i),D)= QS(AT,T(i),D) $\oplus$ QS(SS,T(i),D). In order to reduce branches caused by simulation result, we further assume that qualitative strength of the consumer's behavior attitude and external environment on consumer intention satisfies such condition: STR(AT,T(i),D) > STR(SS,T(i),D). The expert knowledge base of consumer behavioral intention formed by consumer attitude and social environment is shown in Table 5.

Process P (4) shows the process of how consumer makes purchase decisions. Consumer decision depends on the consumer's demand and consumer's behavior intention. Therefore, QS(PUR,T(i),D) =QS(INT,T(i),D) $\oplus$ QS(NEED,T(i),D). In order to reduce branches of simulation result, we also further assume the consumer behavioral intention and demand have the same impact on purchase decision for all three types of consumers: STR(INT,T(i),D)= STR(NEED,T(i),D). At this stage, there are only two results for the output of consumer behavior: to purchase or to give up, but the purchase 
decision produces when consumer's behavior intention and consumer demand are both rising up.

\begin{tabular}{|c|c|c|c|c|}
\hline $\begin{array}{l}\text { Process } \\
\text { name }\end{array}$ & \begin{tabular}{|l|} 
Factor \\
regions
\end{tabular} & Pre-defined Condition & $\begin{array}{l}\text { Qualitative intensity } \\
\text { suppositions }\end{array}$ & Variable state \\
\hline$\overline{P(1)}$ & $\begin{array}{l}C S, B R, A D, \\
P\end{array}$ & NONE & NONE & $\begin{array}{l}Q S\left(P U, T_{(\mathrm{i})}, D\right)=Q S\left(C S, T_{(\mathrm{i}-1)}, D\right) \\
\oplus Q S\left(P, T_{(\mathrm{i})}, D\right) \oplus Q S\left(A D, T_{(\mathrm{i})}, D\right) \\
\oplus Q S\left(B R, T_{(\mathrm{i}-1)}, D\right) \oplus Q S\left(R I S K, T_{(\mathrm{i})}, D\right)\end{array}$ \\
\hline$\overline{P(2)}$ & $\begin{array}{l}P U, \\
S S \\
A T, \quad D E\end{array}$ & $\begin{array}{l}\text { On } T_{(\mathrm{i})} \text { Exist } \\
Q S\left(P U, T_{(\mathrm{i})}, D\right)\end{array}$ & $\begin{array}{l}\operatorname{STR}\left(P U, T_{(\mathrm{i})}, D\right)> \\
\operatorname{STR}\left(S S, T_{(\mathrm{i})}, D\right)\end{array}$ & $\begin{array}{l}Q S\left(A T, T_{(\mathrm{i})}, D\right)= \\
Q S\left(P U, T_{(\mathrm{i})}, D\right) \oplus Q S\left(S S, T_{(\mathrm{i})}, D\right) \\
\oplus Q S\left(D E, T_{(\mathrm{i})}, D\right)\end{array}$ \\
\hline$\overline{P(3)}$ & $\begin{array}{l}S, \\
\text { AT, } \\
I N T\end{array}$ & $\begin{array}{l}\text { On } T_{(\mathrm{i})} \text { Exist } \\
Q S\left(A T, T_{(\mathrm{i})}, D\right) \text { and } \\
Q S\left(S S, T_{(\mathrm{i})}, D\right) \\
\end{array}$ & $\begin{array}{l}\operatorname{STR}\left(A T, T_{(\mathrm{i})}, D\right)> \\
\operatorname{STR}\left(S S, T_{(\mathrm{i})}, D\right)\end{array}$ & $\begin{array}{l}Q S\left(I N T, T_{(\mathrm{i})}, D\right)= \\
Q S\left(A T, T_{(\mathrm{i})}, D\right) \oplus Q S\left(S S, T_{(\mathrm{i})}, D\right)\end{array}$ \\
\hline$\overline{P(4)}$ & $\begin{array}{l}\text { INT, } \\
\text { AT, } \\
\text { PUR, } \\
\text { NEED }\end{array}$ & $\begin{array}{l}\text { On } T_{(\mathrm{i})} \text { Exist } \\
Q S\left(A T, T_{(\mathrm{i})}, D\right) \text { and } \\
Q S\left(I N T, T_{(\mathrm{i})}, D\right) \text { and } \\
Q S\left(\operatorname{NEE} D, T_{(\mathrm{i})}, D\right)\end{array}$ & $\begin{array}{c}\operatorname{STR}\left(N E E D, T_{(\mathrm{i})}, D\right)=S T R(I N T \\
T_{(\mathrm{i})},=\operatorname{STR}\left(A T, T_{(\mathrm{i})}, D\right)\end{array}$ & $\begin{array}{l}Q S\left(P U R, T_{(\mathrm{i})}, D\right)=Q S\left(N E E D, T_{(\mathrm{i})}, D\right) \oplus Q S(I \\
\left.N T, T_{(\mathrm{i})}, D\right) \\
\oplus Q S\left(A T, T_{(\mathrm{i})}, D\right)\end{array}$ \\
\hline$\overline{P(5)}$ & $\begin{array}{l}\text { CS, } \\
\text { PBP }\end{array}$ & $\begin{array}{l}\text { On } T_{(\mathrm{i})} \text { Exist } \\
Q S\left(P, T_{(\mathrm{i})}, D\right) \text { and } \\
Q S\left(B R, T_{(\mathrm{i})}, D\right)\end{array}$ & $\begin{array}{l}\operatorname{STR}\left(P, T_{(\mathrm{i})}, D\right)= \\
\operatorname{STR}\left(B R, T_{(\mathrm{i})}, D\right)\end{array}$ & $\begin{array}{l}Q S\left(C S, T_{(\mathrm{i})}, D\right)= \\
Q S\left(P, T_{(\mathrm{i})}, D\right) \oplus Q S\left(B R, T_{(\mathrm{i})}, D\right)\end{array}$ \\
\hline$\overline{P(6)}$ & $\begin{array}{l}C S, \\
M S, \\
B R\end{array}$ & $\begin{array}{l}\text { On } T_{(\mathrm{i})} \text { Exist } \\
Q S\left(C S, T_{(\mathrm{i})}, D\right) \text { and } \\
Q S\left(M S, T_{(\mathrm{i})}, D\right)\end{array}$ & $\begin{array}{l}\operatorname{STR}\left(C S, T_{(\mathrm{i})}, D\right)= \\
\operatorname{STR}\left(M S, T_{(\mathrm{i})}, D\right)\end{array}$ & $\begin{array}{l}Q S\left(B R, T_{(\mathrm{i})}, D\right)=Q S\left(C S, T_{(\mathrm{i})}, D\right) \\
\oplus Q S\left(B R, T_{(\mathrm{i})}, D\right)\end{array}$ \\
\hline$\overline{P(7)}$ & $\begin{array}{l}C S, B R, A D, \\
P\end{array}$ & $\begin{array}{l}\text { On } T_{(\mathrm{i}+1)} \text { Exist } \\
Q S\left(C S, T_{(\mathrm{i})}, D\right) \text { and } \\
Q S\left(M S, T_{(\mathrm{i})}, D\right)\end{array}$ & $\begin{array}{l}\operatorname{STR}\left(C S, T_{(\mathrm{i})}, D\right)= \\
\operatorname{STR}\left(R I S K, T_{(\mathrm{i})}, D\right)\end{array}$ & $\begin{array}{l}Q S\left(P U, T_{(\mathrm{i}+1)}, D\right)=Q S\left(C S, T_{(\mathrm{i})}, D\right) \\
\oplus Q S\left(P, T_{(\mathrm{i}+1)}, D\right) \oplus Q S\left(A D, T_{(\mathrm{i}+1)}, D\right) \\
\oplus Q S\left(B R, T_{(\mathrm{i})}, D\right) \oplus Q S\left(R I S K, T_{(\mathrm{i}+1)}, D\right)\end{array}$ \\
\hline
\end{tabular}

Table.2: Process knowledge base for consumer behavior qualitative simulation.

\begin{tabular}{|c|c|c|c|c|c|c|c|c|c|c|c|c|}
\hline$Q S\left(P U, T_{(\mathrm{i})}, D\right)$ & ++ & + & -0 & 0 & 0 & & & & & & & $2-$ \\
\hline$Q S\left(C S, T_{(\mathrm{i}-1)}, D\right)$ & +0 & - & $-t$ & 0 & & & 0 & - & & & & \\
\hline$Q S\left(P, T_{(\mathrm{i})}, D\right)$ & +0 & 0 & ) & 0 & & & & 0 & & & & 0 \\
\hline$Q S\left(A D, T_{(i)}, D\right)$ & +0 & 0 & + & - & & & . & 0 & & & & -0 \\
\hline $\mathrm{QS}\left(\mathrm{BR}, \mathrm{T}_{(\mathrm{i}-1)}, D\right)$ & +0 & + & 0 & + & & & + & - & & & & \\
\hline QS(RISK, $\left.\mathrm{T}_{(\mathrm{i})}, D\right)$ & +0 & + & . & + & & & 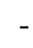 & & & 0 & 0 & $0+$ \\
\hline
\end{tabular}

Table.3: Expert knowledge base of estimated perceived utility of innovators. market share, web advertisement and so on. The qualitative rules $\mathrm{QS}\left(\mathrm{BR}, \mathrm{T}_{(\mathrm{i})}, \mathrm{D}\right) \oplus \mathrm{QS}\left(\mathrm{P}, \mathrm{T}_{(\mathrm{i})}, \mathrm{D}\right)$ is shown in table 6.

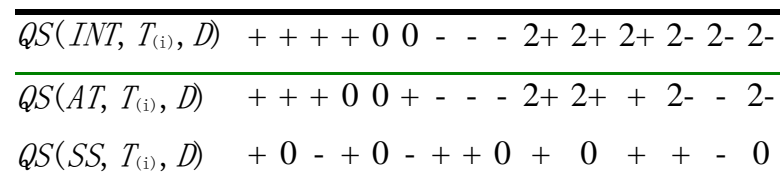

Table.5: The expert knowledge base of consumer behavioral intention.

\begin{tabular}{llllllllllll}
\hline$Q S\left(C S, T_{(\mathrm{i})}, D\right)$ & + & - & - & + & 0 & - & + & + & 0 & + \\
\hline$Q S\left(P, T_{(\mathrm{i})}, D\right)$ & 0 & + & + & - & 0 & 0 & - & - & - & + \\
$Q S\left(B R T_{(\mathrm{i})}, D\right)$ & + & - & 0 & 0 & 0 & - & + & 0 & - & + \\
\hline
\end{tabular}

Table.6: The expert knowledge base of consumer satisfaction caused by brand image and price.

Process P (6) shows the process of how consumer satisfaction degree has impact on the web enterprise's image and market share in the competitive market. Process P (7) shows the process of how consumer perceived utility has been created.

In a competitive market environment, there are some differences among the products and service of conditions, we assume STR(P,T(i),D) $<\mathrm{STR}\left(\mathrm{BR}, \mathrm{T}_{(\mathrm{i})}, \mathrm{D}\right)$, and the image of web enterprise is mainly related to its
Process P (5) shows the process of how consumer satisfaction degree has changed. Consumer satisfaction degree is decided by product image comparison and what consumers pay in this stage. In a certain 
different enterprises provided, such as price, advertisement and brand image, etc, so consumer perceived utility is not the same. This paper assumes that there are three brands in the competitive market, the market share of the three brands is influenced by market share changes among three brands besides consumer's attitudes to brand, brand price, web advertisement and brand image, causality among three brands is shown in Fig 2.
Seen from Fig 2, the market share of the three brands interact each other. Taken brand 1 for an example, the price of the brand, web advertisement and the brand image have impact on the consumer's attitude to brand 1 indirectly and directly. Meanwhile, the changes of market share of brand 2 and brand 3 have negative effect on brand 1 , and so are brand 2 and brand 3 .

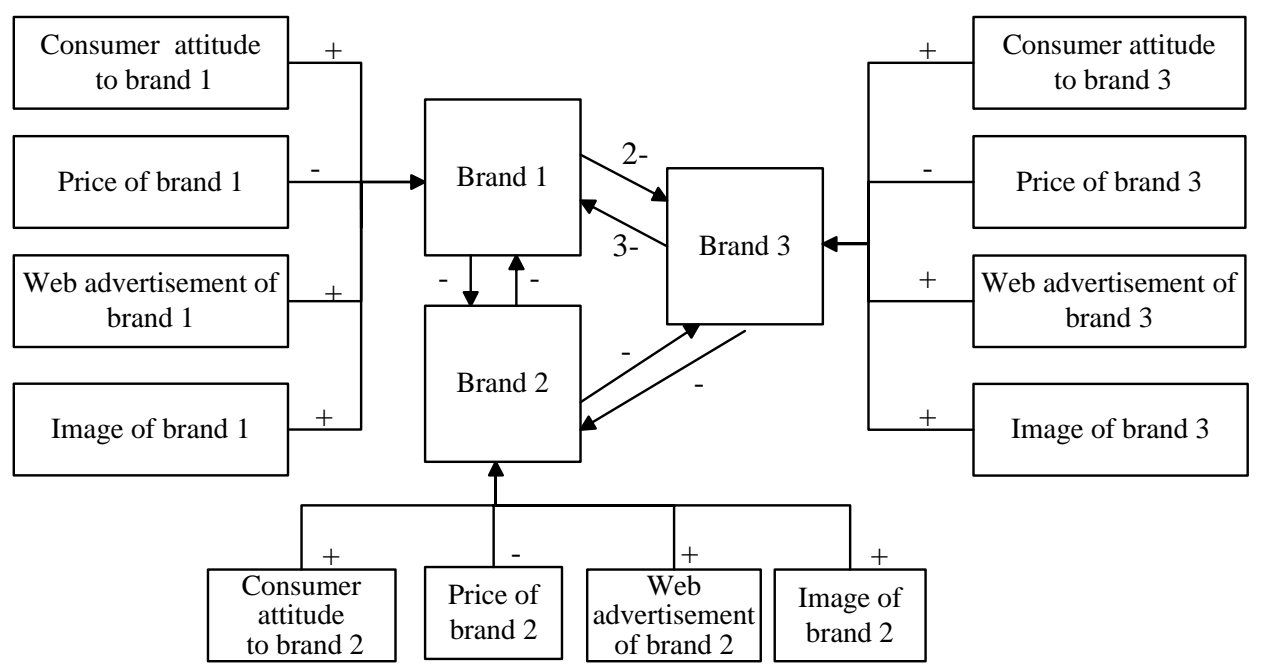

Fig.2: Qualitative causality of market share.

\section{Realization of qualitative simulation system}

There are five modules in the system: type of consumers, decision rules, parameter, simulation result, and help documents. We define three types of customers, innovators, imitators and laggards according to consumer attitude characteristics predefined by the system. At the beginning of simulation, the system read different types of consumer characteristics from knowledge base to know how different marketing strategies have impact on the consumer behavior. There are some differences in decision-making rules for different consumers. For example, the decision-making interface of consumers is shown in the Fig.3.

Seen from Fig 3, users may edit decision rules, qualitative restriction, qualitative strengths and simulation period. After different customer characteristics parameters have been input into the system, three brands parameters have been chosen and simulation has run, finally simulation results have saved.

Taken innovators attitude qualitative simulation for an example, we suppose there are no obvious superiority among three brands and each product price remains unchanged at the time of $t_{0}, t_{1}, t_{2}$, while web advertisement changes. If the rest conditions don't change, innovators qualitative simulation result is shown as the Fig.4.

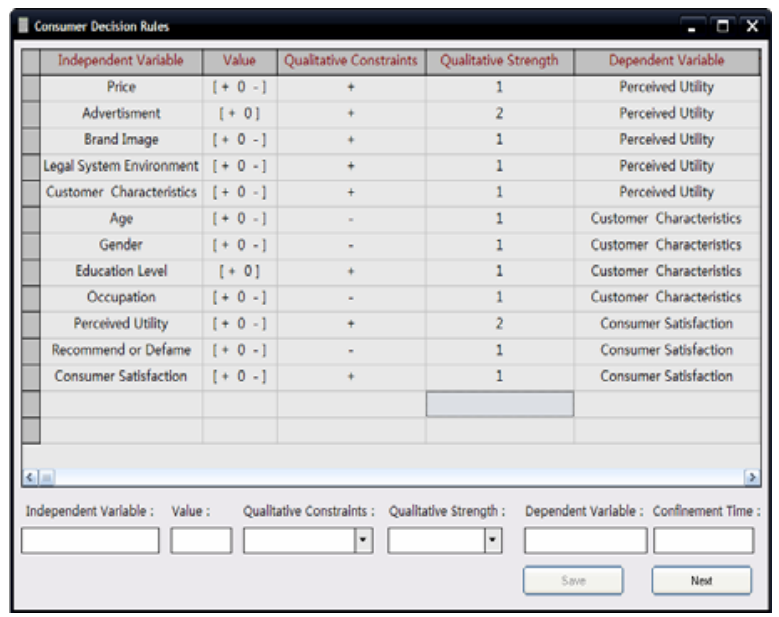

Fig.3: Consumer Decision Rules.

Seen from Fig 4, when there are no obvious superiority among three brands, innovators attitude changes variably with web advertisement changes. 


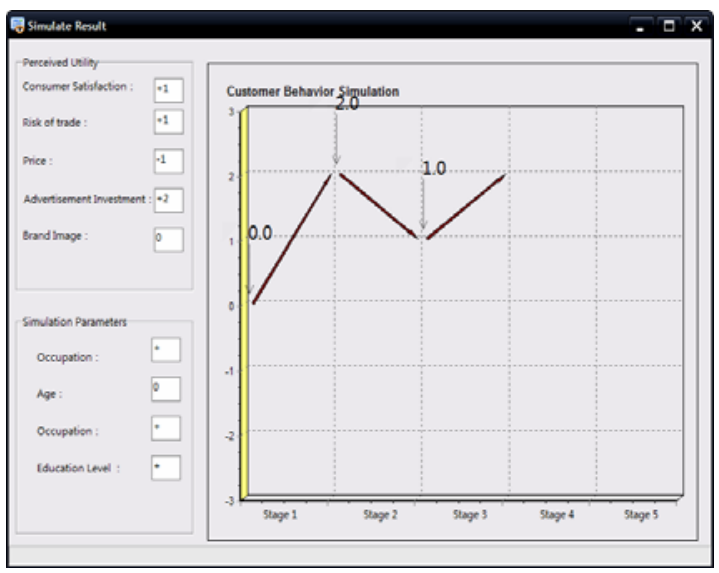

Fig.4: Innovators behavior attitude qualitative simulation.

\section{Conclusions and remarks}

Different from previous research based on consumer decision-making process, we have explored a new marketing research which focuses on the consumer attitude and consumer intention and play little emphasis on the decision process. According to the characteristic of consumer behavior, we have designed the consumer behavior qualitative simulation system by combination qualitative simulation theory with qualitative process theory. What's more, a qualitative process knowledge base has been created for three characteristics of different consumer attitude which means innovators, imitators and laggards, and qualitative strength has been introduced to represent the influenced intensity of different types of consumers based on competitive market background. By VB language, qualitative simulation for consumer behavior has been achieved.

However, how to judge an innovator, imitator or a laggard from the latent consumers needs to be further researched. It is no doubt that social environment may do more than web advertisement and price for a specified product or service, so the system needs to improved to serve for the marketing strategy better and to be more practical in the future.

\section{Acknowledgement}

This work is partially supported by National Nature Science Foundation of Guangxi (Grant No. 0728092).

\section{References}

[1] K.M. Colby, J.B. Watt and J.P. Gilbert, A Computer Method of Psychotherapy: Preliminary Communication. The Journal of Nervous and Mental Disease, 2: 148-152, 1966.
[2] R. Axelrod, The complexity of cooperation: Agent-based models of cooperation and collaboration. Princeton, NJ: Princeton University Press, 1997.

[3] J.D. Berlant, The Use of Partial Qualitative Information with Quantitative reasoning, The University of Texas at Austin, 1991.

[4] F. Guerrin and J. Dumas, Knowledge Representation and Qualitative Simulation of Salmon Redd Functioning Part I: Qualitative Model of Redds, Biosystems, February, 59: 75 84, 2001.

[5] F. Guerrin and J. Dumas, Knowledge Representation and Qualitative Simulation of Salmon Redd Functioning Part II: Qualitative Model of Redds, Biosystems, February, 59: 85108, 2001.

[6] B.J. Kuipers, Qualitative Reasoning: Modeling and Simulation with Incomplete Knowledge, Autometica, 25: 571-585, 1989.

[7] L.A. Zadeh, Outline of a New Approach to the Analysis of Complex Systems and Decision Processes, IEEE Trans. Systems, Man \& Cybernetics, 3: 28-44, 1973.

[8] J. Kleer, Qualitative Reasoning about Physical System: a Return to Roots, Artificial Intelligence, 51: 1-9, 1991.

[9] H. Walter, Melody Y. Kiang, Reiner Lang, Qualitative Reasoning in Business, Finance, and Economics: Introduction, Decision Support Systems, 15: 99-103, 1995.

[10] G.J. Wyatt., Qualitative and Quantitative Simulation of Interacting Markets, Decision Support Systems, 15: 105-113, 1995.

[11] W. Balzer., Towards the Qualitative Plan-based Simulation of International Crises, European Journal of Operational Research, 116: 461-476, 1999.

[12] F.Z. Bai, Z.G. Bao. Fuzzy qualitative simulation of enhanced credibility, Chinese Journal of Automation, pp.45-50, 1998(in Chinese).

[13] C.Y. Liang, T.Y. Huang and S.L. Yang, Improvement of the QSIM Algorithm and Simulation on the Keynesian model, Chinese Journal of Forecast, pp.40-43, 2000(in Chinese).

[14] D.F. Wang and Y.W. Chen. An Integrated Application of Fuzzy Qualitative Modeling and Simulation, System engineering theory \& practice, pp.119-124, 2002(in Chinese).

[15] B. Hu and Z.C. Li, The Qualitative Simulation System for Enterprise Marketing Decision Process, Industrial Engineering and Management, pp.19-22, 2004(in Chinese). 